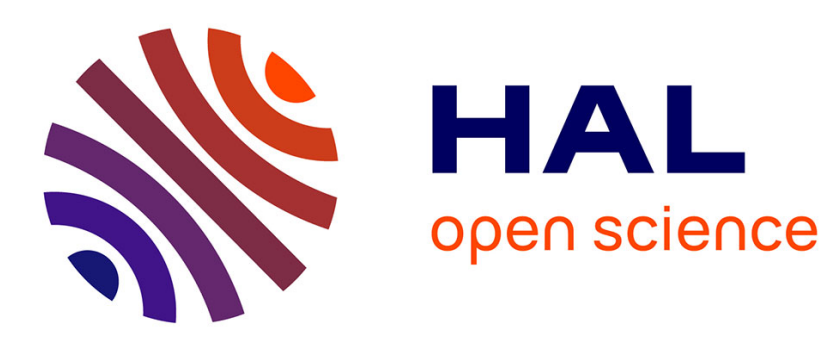

\title{
New technique for in situ sampling of particulate matter and colloids in soil and atmospheric fallout.
}

\author{
N. Perdrial, F. Elsass, N. Liewig
}

\section{To cite this version:}

N. Perdrial, F. Elsass, N. Liewig. New technique for in situ sampling of particulate matter and colloids in soil and atmospheric fallout.. Colloids and Surfaces A: Physicochemical and Engineering Aspects, 2008, 317 (1-3), pp.742-746. 10.1016/j.colsurfa.2007.09.027 . halsde-00259722

\section{HAL Id: halsde-00259722 \\ https://hal.science/halsde-00259722}

Submitted on 30 May 2020

HAL is a multi-disciplinary open access archive for the deposit and dissemination of scientific research documents, whether they are published or not. The documents may come from teaching and research institutions in France or abroad, or from public or private research centers.
L'archive ouverte pluridisciplinaire HAL, est destinée au dépôt et à la diffusion de documents scientifiques de niveau recherche, publiés ou non, émanant des établissements d'enseignement et de recherche français ou étrangers, des laboratoires publics ou privés. 


\title{
New technique for in situ sampling of particulate matter and colloids in soil and atmospheric fallout
}

\author{
Nicolas Perdrial $^{\mathrm{a}, *}$, Françoise Elsass ${ }^{\mathrm{a}, \mathrm{b}}$, Nicole Liewig ${ }^{\mathrm{c}}$ \\ ${ }^{a}$ Centre de Géochimie de la Surface, CNRS-ULP UMR 7517, 1 rue Blessig, 67084 F-Strasbourg Cedex, France \\ ${ }^{\mathrm{b}}$ PESSAC, INRA, RD10, 78026 F-Versailles Cedex, France \\ ${ }^{\mathrm{c}}$ IPHC, Ecologie Physiologie Ethologie, CNRS-ULP UMR 7178, 67087 F-Strasbourg Cedex 2, France
}

Received 22 May 2007; received in revised form 11 September 2007; accepted 14 September 2007

Available online 21 September 2007

\begin{abstract}
This note describes a new technique for in situ sampling of fine particulate matter (PM) including colloids in natural environments. The technique is based on a microlysimeter which is easy to move between field and laboratory and can be routinely used for in situ monitoring. The design of the device aims at limiting bias and artefacts encountered with current sampling methods based on successive field collection of liquid samples, transport, storage and filtration in the laboratory. Samples are directly collected on transmission electron microscopy (TEM) grids, thus totally eliminating the modifications classically due to handling of samples from collection to analysis. Detailed physical and chemical microscopic studies of individual particles can then be performed in order to fully characterize PM in natural media such as soil solutions, atmospheric fallout, rainfall and any aquatic system. This technique can be applied in a number of research fields, such as the characterization and determination of pollution vectors, the tracing of sources of emissions, or investigations on particle interactions.
\end{abstract}

(C) 2007 Elsevier B.V. All rights reserved.

Keywords: In situ monitoring; Lysimeter; Vadose zone; Infiltration water; Analytical electron microscopy

\section{Introduction}

In the last 20 years, the role of particulate matter (PM) including colloids in pollutant transfer has gained increasing attention in soil and groundwater studies [1-5]. It has been shown that both the abundance of PM and the nature of contaminants have a strong influence on pollution transfer and transport in porous media [6,7]. In 1986, McDowell-Boyer et al. [1] deplored the fact that most studies on natural systems had been carried out without paying attention to particulate components and advocated looking into the fundamental phenomena and mechanisms involved. Some of the processes controlling PM transfer were individually and independently explored, but a great majority of the studies performed during the last two decades did not involve natural systems. Because of their complexity and of sampling difficulties, it is impossible to investigate the whole range of matter

\footnotetext{
* Corresponding author. Tel.: +33 39024 0371; fax: +33 390240402.

E-mail addresses: perdrial@illite.u-strasbg.fr (N. Perdrial), elsass@ versailles.inra.fr (F. Elsass),

Nicole.Liewig@c-strasbourg.fr (N. Liewig).
}

and processes involved. Chen and Buffle [8] have pointed out the importance of the physical and chemical characterization of colloids and the challenge in sampling without drastically altering the nature and properties of colloidal material.

Numerous sampling devices already exist for sampling PM in the soil system. These devices, consisting in sampling soil water prior to filtration for PM study, can be separated in two types: tension lysimeters and zero-tension lysimeters. Tension lysimeters are: (i) tension plate lysimeters developed in the 1960s [9, cited in 10], consisting on applying a negative tension onto the plate to create a permanent drainage of water, and (ii) porous cup used since the 1940s [11] consisting on applying a suction force to aspire soil water. Those sampling devices avoid air-water interface but it seems that sampling of PM by filtration of previously pumped groundwater can introduce artefacts due to high pumping rates or alteration in chemical and physical properties [12,13]. Zero-tension lysimeters are of four types: (i) lysimeters sensus stricto [14, cited in 15]; (ii) plate lysimeters [16, cited in 17]; (iii) gutter lysimeters [18,19], and (iv) wicks lysimeters [20]. These devices are all based on the same principle: sampling gravitational water. However, the validity of information 
given by such devices has been often discussed and it is today accepted that: (i) a soil-air interface is artificially created into the soil $[15,17,21,22]$, and (ii) a contamination from vessels, or coagulation and microbial changes during storage is possible [8]. Moreover, none of these devices have been designed to sample directly PM and colloids for individual particle investigation.

Based on the recent review paper of McCarthy and McKay [7], it appears that the sampling of colloids/PM in the vadose zone as well as in saturated groundwater is a key challenge that needs to be addressed properly. Moreover, characterizing the atmospheric input of PM on soil surface is of prime interest in PM studies [23,24]. It is therefore important to develop techniques that enable the characterization of individual PM present in atmospheric deposits and in gravitational water in a state as close as possible to natural conditions.

We propose here a new sampling method minimizing disturbances to the nature and organisation of the PM fraction in order to better investigate the characteristics and/or evolution of such material by analytical transmission or scanning electron microscopy (TEM, SEM).

\section{Sampling device}

\subsection{Basic principle of the device}

The basic principle of the field device consists in real time filtration of percolating water by lysimetry. The microlysimeter used for that purpose is a filtration box filled with inert sand and placed in contact with the soil at the desired sampling depth. The particle collector consists in TEM grids inserted in the sand bed and intercepting the PM by simple gravitational deposition.

The vertical flow of infiltrating water is isolated from lateral flow by confining the soil column in a PVC tube. A stopper fit to the bottom of the tube and drilled with holes allows the drainage of the soil solution. The microlysimeters can be replaced regularly for periodic monitoring. An adapted handling device allows lifting and dropping the tube with no further perturbation of the soil column confined inside the tube.

\subsection{Microlysimeter}

The essential part of the device is the microlysimeter (Fig. 1a). The container is a two stage Millipore ${ }^{\Theta}$ filtration cell for fluid analyses with a $4.5 \mathrm{~cm}$ internal diameter. In order to facilitate the inflow of water, the cover and the bottom of the box are drilled with holes. At the lower stage of the box a rigid I-Vyon ${ }^{\circledR}$ filter is placed under a plastic basket containing carbon coated $\mathrm{Cu}$ and Ti TEM grids. This Vyon-type filter with a pore size of $80 \mu \mathrm{m}$ constitutes a support for the whole device. Grids are embedded in pure inert silica sand (diameter: $100-200 \mu \mathrm{m}$ ). A cellulose nitrate filtration membrane is mounted over the sand bed and clamped between the two stages of the filtration cell. The membrane is covered with sand so as to fill completely the upper stage of the cell topped with a nylon filter (pore size: $100 \mu \mathrm{m}$ ). This assembly is functioning as a lysimeter. The soil solution collected at the upper stage of the cell is filtered through the cellulose membrane (i.e., at $5 \mu \mathrm{m}$ ), which allows the collection on the underlying grids of all the size fractions of PM from nanoparticles to the size of the porosity of the selected membrane. We recommend a rather large porosity of the membrane to keep it free of clogging and avoid the bias due to the interaction of PM with the pore edges that may occur with too small pore diameters. The design of the device is avoiding any air interface with a continuum of porosity due to the sand filling. The nylon filter has a rather large porosity $(100 \mu \mathrm{m})$, assumed to be close to the soil porosity and then let any PM and colloids reach the cellulose membrane, which is the truly restricting size filter. However, depending on the sampled environment and sampled objects, any other filter porosity can be adapted to the device. The use of a cellulose nitrate membrane as described below allows micro-biological analysis of the filter and SEM observation.

\subsection{Field device}

The field device (Fig. 1b) is based on PVC tubes driven vertically into the soil. The PVC tubes have an internal diameter of $12.7 \mathrm{~cm}$ and their length is adapted to the soil depth selected for a given study. This device may be used either to study a complete soil column, or various depths selected according to specific study criteria such as differentiated soil horizons, mod-

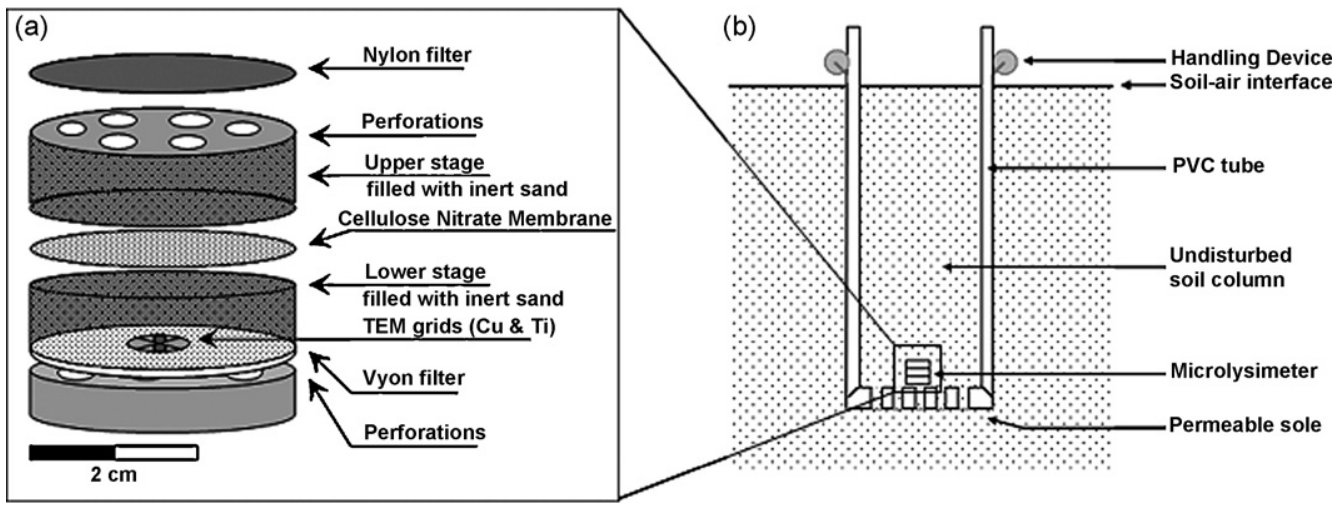

Fig. 1. Description of the sampling device. (a) Assemblage of the microlysimeter. (b) Cross section of the field installation for sampling PM in soil infiltration water. 


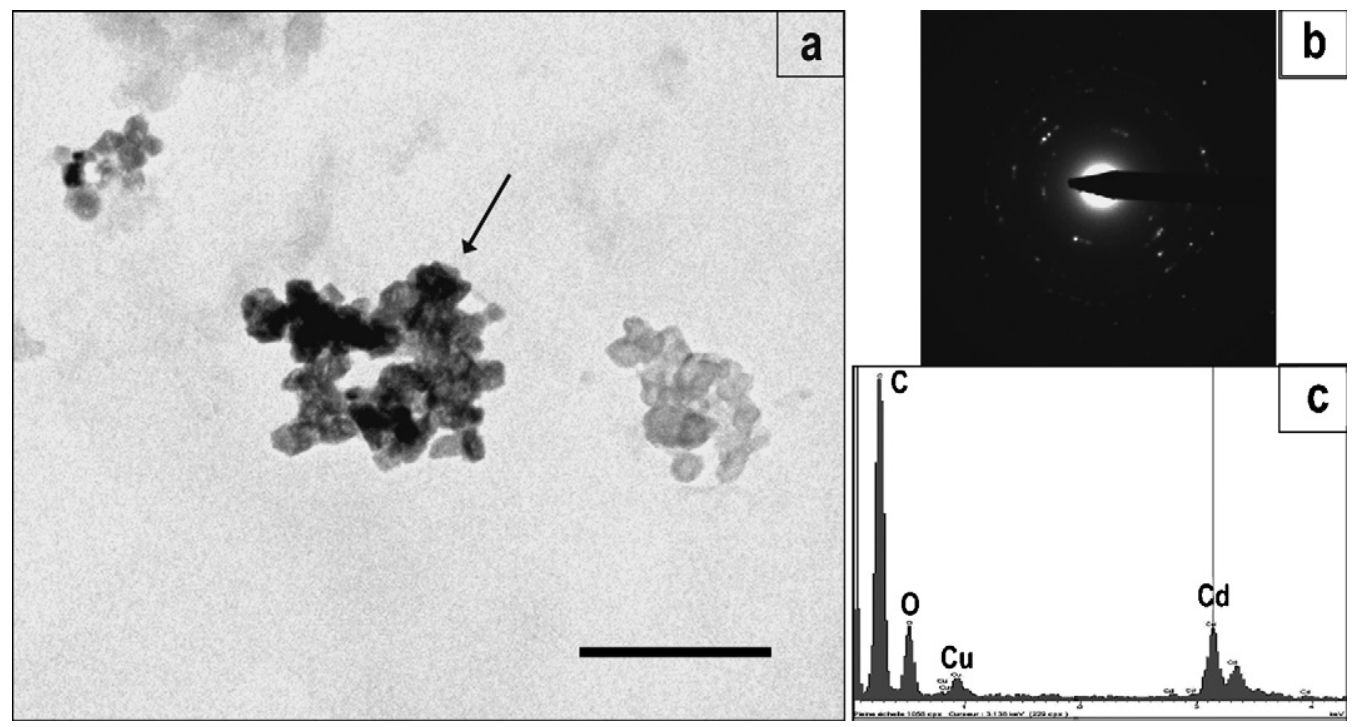

Fig. 2. Example of characterization of individual particles by analytical electron microscopy. (a) TEM micrograph of a cadmium-rich PM present in infiltration water of a tillage soil. Scale bar: $0.2 \mu \mathrm{m}$. (b) Microdiffraction pattern of particle arrowed on (a). (c) Energy dispersive X-ray analysis of the particle arrowed on (a). C peak is due to the carbon coating of the grid and to the presence of organic matter. $\mathrm{Cu}$ peak is due to the copper grid.

ifications in porosity, or biological zonings. It is recommended to let the field device settle for a period to allow the sealing of cracks generated during the introduction of the tube in the soil. After the settling period, the tube is pulled out, the bottom stopper is removed, the particle collector is placed at the bottom of the soil column and the tube dropped back in place. To remove the particle collector and replace it with another one for monitoring purposes, the protocol is exactly the same.

In addition to the set of PVC tubes equipped with microlysimeters, a $500 \mathrm{~mL}$ filtration box is used at the surface of the soil, based on the same filtration principle than the particle collector device fitted to the soil columns. The filtration box is designed to filter rainwater and collect the atmospheric inputs.

According to the sampling intervals, the particle collector is recovered and dismantled in the laboratory under a glove box to avoid dust and bacterial contamination. Grids are washed with $20 \mu \mathrm{L}$ of purified and sterilized water to eliminate excess soil solution and avoid precipitation of dissolved matter. Observation of aggregates and organic particles proves that this washing is not affecting the particles integrity; however, the loss of a small amount of particles is possible. Then the grids are air dried prior to analysis in the microscope.

\section{Discussion}

As the device placed directly inside the soil is of very small size (a few centimeters), its effect on the hydrologic properties is equivalent to that of a small pebble, and as the TEM grid is $3 \mathrm{~mm}$ in diameter its effect is equivalent to that of a large sand grain. This does not significantly modify the drainage, the $\mathrm{pH}$, or the temperature of the soil solution near the device. The grid can be considered as similar to an inert soil component or pore wall on which PM are collected by simple deposition. The TEM grids loaded with PM allow: (i) performing all analytical TEM techniques such as microanalysis (EDS), high resolution images (HRTEM), microdiffraction (SAED), providing chemical composition and physical characterization, as well as permitting image analysis for size distribution or
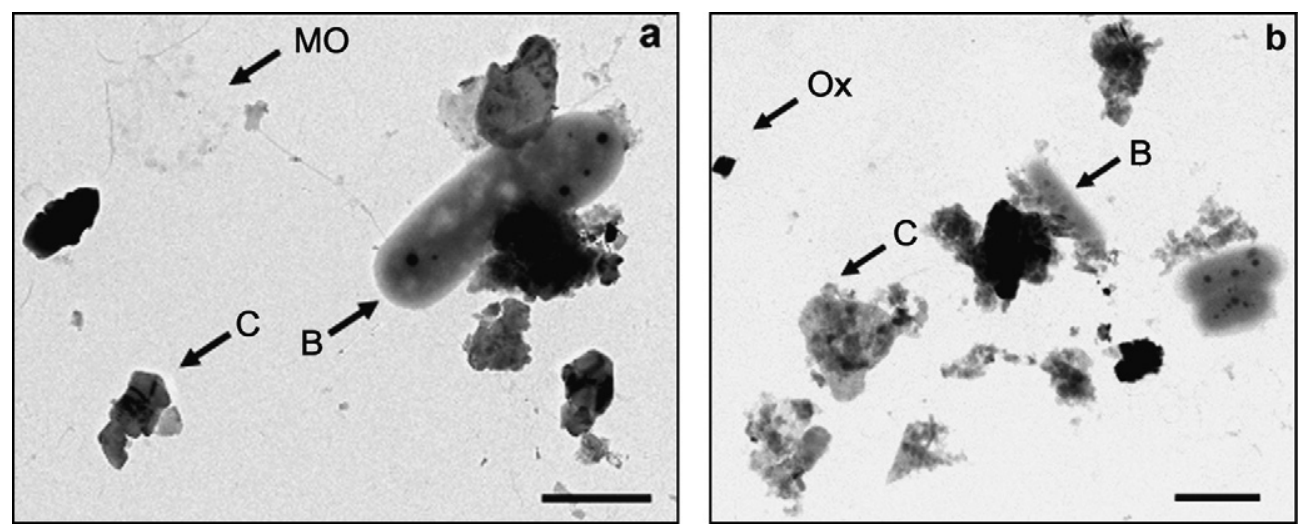

Fig. 3. Examples of naturally occurring aggregates. (a) TEM micrographs of atmospheric PM. MO: organic matter; C: individual clay particle; B: bacteria associated with clays. (b) TEM micrograph of soil infiltrating water PM. Ox: metal oxide; B: bacteria associated with minerals; C: weathered clay. Scale bar: $1 \mu \mathrm{m}$. 
shape studies (Fig. 2); (ii) performing additional observations by scanning electron microscopy such as SEM or ESEM investigations on grids or on filters; (iii) storing them in a dry state for months/years without altering particle characteristics.

The examination of sampling grids with TEM shows the presence of different types of colloidal PM and their assemblages in the field conditions. Samples from soil solutions and atmospheric fallout are representative of both mineral and biological components that are known to exist as PM in natural environments [7,10]. Moreover, it appears clearly that naturally occurring aggregates remain undisturbed by applying this technique (Fig. 3). Such aggregates are usually not studied in natural environments because of disaggregation caused by the tension applied during sampling and/or centrifugation of water to concentrate PM. Whereas aggregation processes, investigated in laboratory experiments, had been recently shown to be an important mechanism of PM and colloid-facilitated transport in soils [25-28].

One of the potential biases of the method is the installation of the field device. The field device is settled following the same protocol as conventional lysimeter settling. It has been shown that this settling is modifying the flow on the sidewall of the tube [29]. Since these authors highlighted the fact that the flow is not modified in the center of the tube; we assume that it is the same here. Moreover, we recommend to perform the first driving of the field device in a wet season and wait at least one month prior to sampling in order to let the soil heal up and eliminate possible discharge of PM due to the installation of the device. Another possible inconvenient is the difference in capillary pressure between the soil and the microlysimeter due to a difference of porosity. However, the diameter of the sand $(100-200 \mu \mathrm{m})$ is assumed to be inferior or similar to the soil porosity, then no barrier is created and the capillary force is normal or slightly positive. The size of the sand has to be selected according to the average porosity of the soil and a mixing of two or three different sand sizes is recommended in the upper part of the microlysimeter. A smaller diameter has to be selected for the lower part to create a slight positive capillary pressure and avoid a barrier due to the rather small porosity of the membrane.

\section{Conclusion}

To conclude, it appears that the design of this field device is a great step forward in the in situ monitoring and physicochemical characterization of individual PM from atmospheric input to soil solution. The sampling intervals are easy to adjust to the investigated subject, the device can be used indifferently for a short event (rain, storm), for a period of a week, for a month or a season. However, the tests performed with our device have shown that for soil nanoparticles a period of more than 2 to 3 months is not recommended because of problems such as clogging of the membrane as well as the overloading of PM on the grids.

\section{Acknowledgements}

A Ph.D. fellowship to Nicolas Perdrial by the French Ministry of National Education is thankfully acknowledged. We gratefully thank BRGM Alsace, INRA Colmar and BEF team from INRA Nancy for special attention to our work, advice and technical support for field experiments.

\section{References}

[1] L.M. McDowell-Boyer, J.R. Hunt, N. Sitar, Particle transport through porous media, Water Resour. Res. 22 (13) (1986) 1901-1921.

[2] J.F. McCarthy, J.M. Zachara, Subsurface transport of contaminants; mobile colloids in the subsurface environments may alter the transport of contaminants, Environ. Sci. Technol. 23 (1989) 496-502.

[3] A.N. Crossan, N. Lee, R. Sharma, I.R. Kennedy, R. Beckett, Assessment of the distribution of pesticides on soil particle fractions in simulated irrigation run-off using centrifugal SPLITT fractionation and ELISA, Anal. Chim. Acta 468 (2002) 199-208

[4] M.B. McGechan, D.R. Lewis, Transport of particulate and colloid-sorbed contaminants through soil. Part I: General principles, Biosyst. Eng. 83 (3) (2002) 255-273.

[5] L. Citeau, F. Gaboriaud, F. Elsass, F. Thomas, I. Lamy, Investigation of physico-chemical features of soil colloidal suspensions, Colloids Surf. A 287 (1-3) (2006) 94-105.

[6] S.B. Roy, D.A. Dzombak, Chemical factors influencing colloid-facilitated transport of contaminants in porous media, Environ. Sci. Technol. 31 (3) (1997) 656-664.

[7] J.F. McCarthy, L.D. McKay, Colloid transport in the subsurface: past, present and future challenges, Vadose Zone J. 3 (2004) 326-327.

[8] Y.-W. Chen, J. Buffle, Physicochemical and microbial preservation of colloid characteristics of natural water samples I: experimental conditions, Water Res. 30 (9) (1996) 2178-2184.

[9] D.W. Cole, Alundum tension lysimeter, Soil Sci. 85 (1958) 293-296.

[10] G.H. Wagner, Use of porous ceramic cups to sample soil water within the profile, Soil Sci. 94 (1962) 379-386.

[11] E.F. Wallihan, An improvement in lysimeter design, J. Am. Soc. Agron. 32 (1940) 395-404.

[12] R.W. Puls, R.M. Powell, Acquisition of representative ground water quality samples for metals, Ground Water Monit. Rev. 12 (1992) 167-176.

[13] N. Domange, C. Gregoire, V. Gouy, M. Tremolieres, Effect of ceramic cups ageing on the capacity to assess pesticide concentration, C.R. Geosci. 336 (1) (2004) 49-58.

[14] P. DeLaHire, Sur l'origine des rivières, Hist. Acad. R. Sci. 1 (1703) 1-6.

[15] D.W. Cole, S.P. Gessel, E.E. Held, Tension lysimeter studies of ion and moisture movement in glacial till and coral atoll soils, Soil Sci. Soc. Proc. 25 (1961) 321-324

[16] J.S. Joffe, Lysimeter studies: I. Moisture percolation through the soil profile, Soil Sci. 34 (1932) 123-142.

[17] R. Giesler, U.S. Lundstrom, H. Grip, Comparison of soil solution chemistry assessment using zero-tension lysimeters or centrifugation, Eur. J. Soil Sci. 47 (3) (1996) 395-405.

[18] R.E.J. Boerner, An inexpensive, tension-free lysimeter for use in sandy soils, Bull. Torrey Botanical Club 109 (1) (1982) 80-83.

[19] B.L. Haines, J.B. Waide, R.L. Todd, Soil solution nutrient concentrations sampled with tension and zero-tension lysimeters: report of discrepancies, Soil Sci. Soc. Am. J. 46 (3) (1982) 658-661.

[20] K.W. Brown, J.C. Thomas, M.W. Holder, Development of a capillary wick unsaturated zonepore water sampler. Coop. Agreement CR812316-01-0. USEPA Environ. Monit. Syst. Lab., Las Vegas, NV. (1986).

[21] L.A. Richards, O.R. Neal, M.B. Russel, Observations on moisture conditions in lysimeters: II, Soil Sci. Soc. Am. J. 4 (1938) 55-59.

[22] E.A. Colman, A laboratory study of lysimeter drainage under controlled soil moisture tension, Soil Sci. 62 (1946) 365-382.

[23] M. Pósfai, J. Li, J.R. Anderson, P.R. Buseck, Aerosol bacteria over the Southern Ocean during ACE-1, Atmos. Res. 66 (2003) 231-240. 
[24] S.O. Ndzangou, M. Richer-LaFlèche, D. Houle, Anthropogenic Pb accumulation in forest soils from Lake Clair watershed: Duchesnay experimental forest (Québec, Canada), Appl. Geochem. 21 (2006) 21352147.

[25] C.A. Aurell, A.O. Wistrom, Coagulation of kaolinite colloids in high carbonate strength water, Colloids Surf. A 168 (3) (2000) 227-285.

[26] R.A. Alvarez-Puebla, J.J. Garrido, Effect of $\mathrm{pH}$ on the aggregation of a gray humic acid in colloidal and solid state, Chemosphere 59 (5) (2005) 659-667.
[27] K. Itami, H. Fujitani, Charge characteristics and related dispersion/flocculation behavior of soil colloids as the cause of turbidity, Colloids Surf. A 265 (1-3) (2005) 227-285.

[28] A. Majzik, E. Tombacz, Interaction between humic acid and montmorillonite in the presence of calcium ions II. Colloidal interactions: charge state, dispersing and/or aggregation of particles in suspension, Org. Geochem. 38 (8) (2007) 1330-1340.

[29] D.L. Corwin, Evaluation of a simple lysimeter-design modification to minimize sidewall flow, J. Contam. Hydrol. 42 (1) (2000) 35-49. 